\title{
Characterization and corrections for clamp-on fluid temperature measurements in turbulent flows
}

Bijan Nouri ${ }^{1}$, Marc Röger ${ }^{1}$, Nicole Janotte ${ }^{2}$ and Christoph Hilgert ${ }^{1}$

${ }^{1}$ German Aerospace Center (DLR), Institute of Solar Research, Plataforma Solar de Almería (PSA), 04200 Tabernas, Spain

${ }^{2}$ German Aerospace Center (DLR), Institute of Solar Research, Linder Höhe, 51147 Köln, Germany

E-mail: Bijan.nouri@dlr.de

Keywords

Temperature measurement, fluid temperature, turbulent flow, PT100, correction function, clamp on system, performance testing, acceptance testing, CSP, solar power plant, parabolic trough

\section{Abstract}

A clamp-on measurement system for flexible and accurate fluid temperature measurements for turbulent flows with Reynolds numbers higher than 30,000 is presented in this paper. This non-invasive system can be deployed without interference with the fluid flow while delivering the high accuracies necessary for performance and acceptance testing for power plants in terms of measurement accuracy and position. The system is experimentally validated in the fluid flow of a solar thermal parabolic trough collector test bench, equipped with built-in sensors as reference. Its applicability under industrial conditions is demonstrated at the 50$\mathrm{MW}_{\mathrm{el}}$ AndaSol-3 parabolic trough solar power plant in Spain. A function based on large experimental data correcting the temperature gradient between the measured clamp-on sensor and actual fluid temperature is developed, achieving an uncertainty below $\pm 0.7 \mathrm{~K}(2 \sigma)$ for fluid temperatures up to $400^{\circ} \mathrm{C}$.

In addition, the experimental results are used to validate a numerical model. Based on the results of this model, a general dimensionless correction function for a wider range of application scenarios is derived. The clamp-on system, together with the dimensionless correction function, supports numerous combinations of fluids, pipe materials, insulations, geometries and operation conditions and should be useful in a variety of industrial applications of the power and chemical industry where temporal non-invasive fluid temperature measurement is needed with good accuracy. The comparison of the general dimensionless correction function with measurement data indicates a measurement uncertainty below $1 \mathrm{~K}(2 \sigma)$. 


\section{Introduction}

Many applications exist for heat conduction problems, where the desired temperatures or heat flux are estimated. Beck et al. [1] and Wen-Lih et al. [2] investigate heat conduction problems to estimate an unknown surface heat flux respectively heat transfer rate on the external wall of a pipe system. Lu et al. [3] developed a three-dimensional inverse heat conduction analysis based on the conjugate gradient method to estimate the inner wall temperature fluctuations in a pipe elbow using outer wall temperature fluctuations. For the clamp-on application presented in this work, the desired fluid temperature is unknown and has to be approximated from a measured pipe surface temperature. In order to determine the fluid temperature within the needed accuracies, the quality of the initial measurements is of great importance. The principal issue of a clamp-on temperature measurement approach deriving the fluid temperature at elevated temperatures from the external pipe surface temperature measurement is to realize a good thermal coupling between sensor and surface and to reduce ambient influences on the measurement. High temperature differences between fluid and pipe surface which fluctuate strongly with ambient conditions would increase the uncertainties of the approximated fluid temperature. The smaller the temperature correction a clamp-on system needs for correct readings, the less effect has the unavoidable uncertainty in the correction function on the final fluid temperature result.

Different clamp-on measurement systems are commercially available. Most of these systems are designed for operation temperatures below $200^{\circ} \mathrm{C}$ and have uncertainties not sufficient for performance and acceptance testing for power plants, for example. More sophisticated commercial systems like the Rosemount 0085 Pipe Clamp Sensor are designed for higher temperatures. However, there are few reliable uncertainties given by the manufacturer on these systems. A numerical case study for the Rosemount 0085 Pipe Clamp Sensor is conducted by Gorman et al. [4] to clarify the accuracy of the system. In total eight cases with different operating parameters are investigated. The key findings are a set of dimensionless variables for each case (dimensionless temperatures, Reynolds and Prandtl numbers). Temperature correction for the clamp-on temperature can be determined by these values using an algebraic correction formula. For additional cases interpolation is necessary. A presented example stated a temperature correction as high as $6 \mathrm{~K}$ between fluid and measured pipe surface temperatures at an absolute fluid temperature around $51^{\circ} \mathrm{C}$.

Clamp-on temperature measurement applications for hydraulic systems in a temperature range below $80^{\circ} \mathrm{C}$, without insulation and laminar flow are investigated under laboratory conditions by Wei Cai et al. [5].

The lack of adequate commercially available clamp-on systems which fulfil the requirements of a temperature range up to $400^{\circ} \mathrm{C}$ and uncertainties to determine the fluid temperature below $1 \mathrm{~K}(2 \sigma)$ is the motivation of the development of a clamp-on measurement system based on PT100 resistance thermometers presented in the following.

\section{The need for accurate fluid temperature readings}

A variety of scenarios in different industries exist, in which an additional accurate temperature measurement is needed for a short time period (e.g. due to recalibration of sensors, 
troubleshooting in a running process, during performance and acceptance testing). Ideally, this additional measuring point is implemented without interference of the running process operation. In this work, we describe the case of performance and acceptance testing of solar fields from line focusing concentrating solar power (CSP) plants. In CSP plants, a solar field collects and concentrates the sun irradiance and transforms it to thermal energy. This thermal energy needs to be measured during performance and acceptance testing of the solar field after erection or during optimization. Solar fields of line focusing solar power plants consist of large numbers of collectors arranged in parallel rows. These concentrate incident solar radiation and transfer it to a heat transfer fluid (HTF) flowing through the absorber tube of a receiver situated in the focal line. The heat is used in a Rankine process to drive a turbine generating electricity or for process heat applications. An overview of parabolic trough collectors and their application is given by [6]. The solar field is the sole heat source and its performance is thus crucial for the plant operation, production and profitability.

The regular solar field temperature measurement instrumentation is selected in view of the reliability, durability and robustness needed to resist harsh environmental conditions over the entire operating life of the power plant (25 years and more) often at the expense of resulting measurement accuracy [7]. Nevertheless, there are various applications in which higher measurement accuracy rather than durability is needed. For example, during the commissioning or after major maintenance services of the solar field, a variety of performance tests have to be conducted, which require temporary, accurate temperature measurement at different locations [8]. Furthermore, these can serve to review the existing measurement system during normal operation.

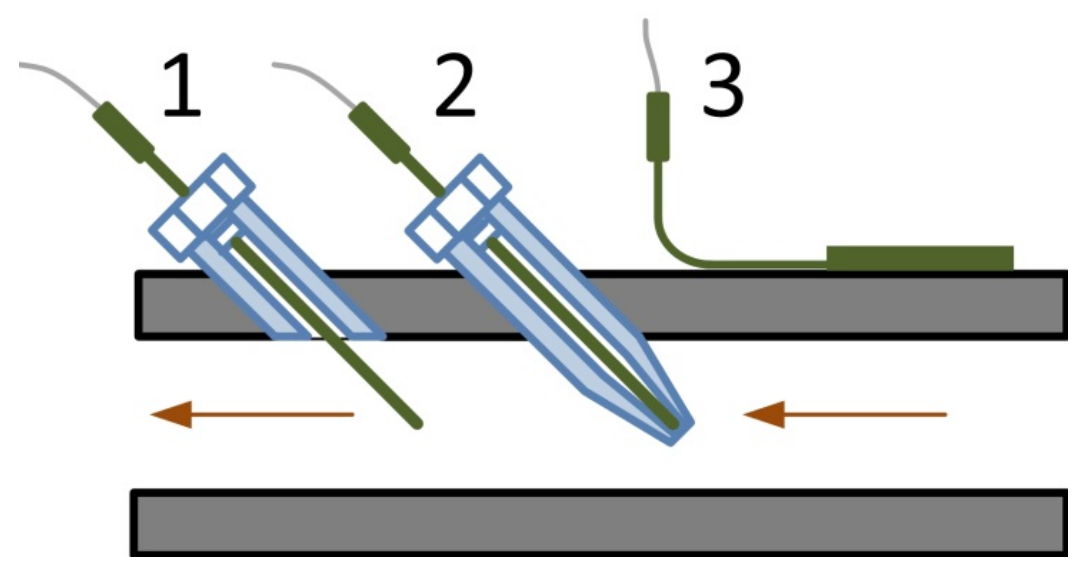

Figure 1: Different temperature measurement approaches on pipes. 1) Wetted sensor using thermowell with compression fitting 2) Embedded sensor using closed thermowell 3) Sensor clamped on pipe surface

Different temperature measurement approaches on pipes are illustrated in Figure 1. Most accurate measurements use wetted sensors which are in direct contact with the fluid by means of an open thermowell. This system bears the risk of leakages, if the sensor mounting is not done properly, especially with higher pressures. An exchange of sensors requires draining of the respective pipe section. Closed thermowells, where the sensor is embedded into the pipe but not wetted, are less vulnerable. However, if there is no thermowell available at the desired measurement position, the mounting of additional recently calibrated embedded sensor interferes directly with the plant operation causing downtime (for part of the system). The required constructive measures also increase the risk of leakage of the heat 
transfer fluid, which could lead to costly technical incidents or even to health and safety issues. Clamp-on temperature sensors represent an alternative approach, since they can be mounted during regular plant operation without any significant interference or the risk of major technical incidents. Furthermore, independence and traceability of performance measurement can be achieved by clamp-on measurement system. The main challenge lies in their accuracy as a systematic difference between the fluid and the clamp-on sensor on the outer tube shell is to be accounted for accurately. This difference results from the thermal resistance of the interfaces (fluid to pipe wall and pipe wall to clamp-on sensor) and the pipe walls, and the ambient conditions the system is exposed to. Its markedness depends on the materials used, pipe geometry, clamp-on design and mounting quality as well as the HTF operation and ambient conditions.

The present work considers a clamp-on temperature measurement application for temperatures up to $400^{\circ} \mathrm{C}$ in outdoor facilities with insulated piping and turbulent flow. A specific correction function for the described application in solar fields of line focusing CSP plants with thermal oils as HTF, and pipe properties corresponding to current EuroThrough [9] collector loop piping is developed (see section 4). The requirements for the clamp-on system for this paper are: Measuring range up to $400^{\circ} \mathrm{C}$ or higher with an uncertainty in the fluid temperature below $1 \mathrm{~K}\left(2 \sigma\right.$, at $\left.400^{\circ} \mathrm{C}\right)$, verifiable calibration and easy recalibration, easily mountable system without interference of plant operation, and suitability for several weeks of use in the solar field

With the help of a general correction function resulting from a dimensional analysis a wider range of clamp-on applications with different HTFs, pipe geometries and operating conditions is to be accounted for. This allows the application of the developed clamp-on system for other plants e.g. in the power or chemical industry and even completely different applications with similar demands in terms of uncertainties but deviating operation and boundary conditions. The presented general correction function in this paper is demonstrated to be valid for Reynolds numbers larger than 30,000. Applications with laminar or transitional flow regimes are not covered here. For the laminar-turbulent transition regime in pipes (Re being between 2300 and 4000), Abraham et al. [10] show that the Gnielinsky modification of the PetukhovPopov equation overestimates the convective heat transfer and presents a modified equation for the friction factor for fully developed flows in the low Reynolds number end of the transition regime. The resulting Nusselt numbers are in better agreement to the laminar flow values compared to the standard Gnielinsky equation. These results in mind, it seems conceivable to transfer the procedure presented in this paper also to laminar and transitional flow regimes, however this has to be shown in future works. 


\section{Description and qualification of the measurement systems}

PT100 resistance thermometers are selected for the system due to their comparatively low measurement uncertainty [11], good durability and the appropriate measuring range. Alternative temperature sensors would be thermistors, which are composed of semiconductor materials, or thermocouples which use the so called Seebeck effect.

The non-invasive clamp-on PT100 sensors are mounted on the outside of the pipe using hose clamps. A sensor holder with matching drillings in combination with high temperatureresistant thermal grease applied at the contact surfaces ensures a good thermal coupling and homogenization of the temperature around the PT100 sensor. Ambient influences are reduced by means of temperature shields (see Figure 2) and insulation. Metal sheathed sensors with a length of $400 \mathrm{~mm}$ and a $90^{\circ}$ angle at half the length are used (as sketched in Figure 1 and Figure 5). The PT100 protective metal sheath has to be bent, in order to keep the vulnerable interconnection of the protective sheath and signal cable away from the hot pipe and outside the insulation.

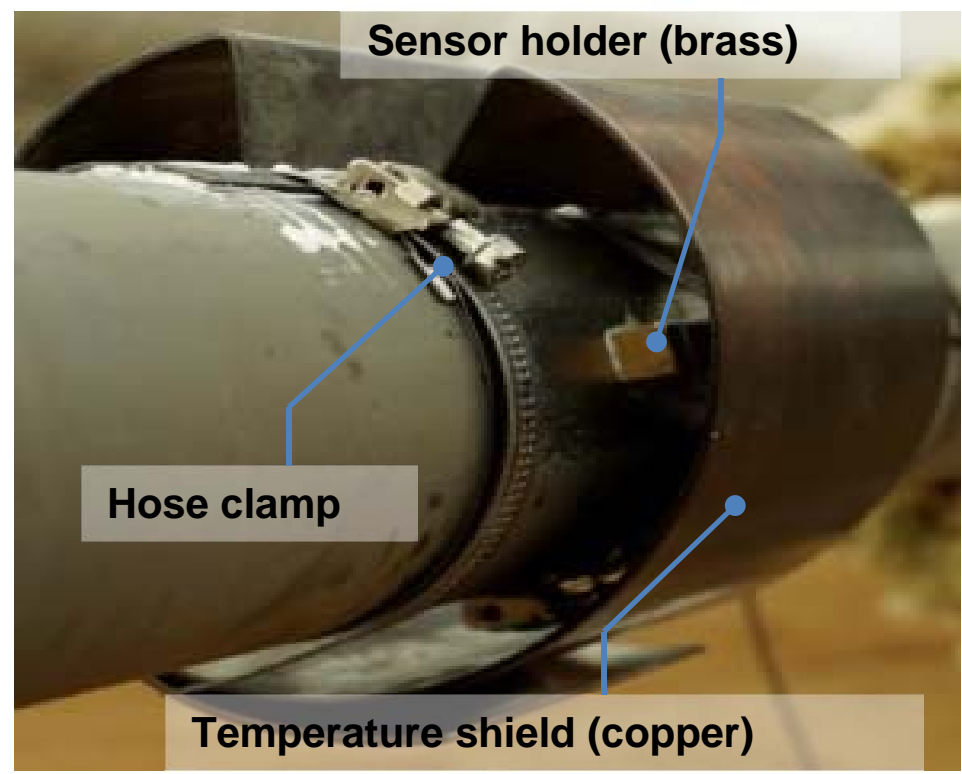

Figure 2: Mounted clamp-on measurement setup without insulation

Using the KONTAS testing facility of the Plataforma Solar de Almería (PSA) [18], the clampon measuring setup is tested and qualified under actual power plant conditions. The influence of different geometries and materials for the sensor holder, temperature shields and insulation as well as the influence of different operation conditions with varying Reynolds numbers and temperature gradients are investigated. The qualification of the measurement system is based on a comparison of the clamp-on sensors with reference sensors of the same type embedded close to the clamp-on position. The setup of test and reference sensors is shown in Figure 5 and the PT100 sensor specifications listed in Table 1. 
Table 1: Specification of PT100 sensors used as inline reference temperature sensors and for the clamp-on setup

\begin{tabular}{|l|l|}
\hline Type & PT100 \\
\hline Class & A according to DIN EN \\
& 60751 \\
\hline Nominal resistance & $100 \Omega @ 00^{\circ} \mathrm{C}$ \\
\hline Sheath diameter & $3 \mathrm{~mm}$ \\
\hline Sheath length & $400 \mathrm{~mm}$ \\
\hline Immersion depth (only embedded sensors) & $170 \mathrm{~mm}$ \\
\hline Connection method & 4 -wire connection \\
\hline Operating temperature & $-75^{\circ} \mathrm{C}$ to $600^{\circ} \mathrm{C}$ \\
\hline
\end{tabular}

\subsection{PT100 calibration and preliminary study}

Uncertainties in between $\pm 1 \mathrm{~K}(1 \sigma)$ are expected for a class A PT100 as defined by the IEC 60751 at absolute temperatures around $400^{\circ} \mathrm{C}$. Gam et al. [12] and Zvizdić et al. [13] investigate the thermal hysteresis effects in industrial platinum resistance temperature detectors. Both groups observed a hysteresis around $0.1 \mathrm{~K}$ for absolute temperatures of $400^{\circ} \mathrm{C}$. Natural aging effects due to long-term exposure to any combination of heat, humidity, vibration, temperature cycling and mechanical shock were studied by Hashemian [14]. A general drift of around $\pm 0.2 \mathrm{~K}$ was found over an aging period of 18 months. Due to the general stability of PT 100 the desired accuracies as stated in section 1 of below $\pm 1 \mathrm{~K}$ at $400^{\circ} \mathrm{C}$ seem obtainable in consideration of additional calibrations.

All PT100 involved in the measuring campaign, are previously calibrated according to the comparative method described in the DAkkS-DKD-R 5-1 guideline [15]. An AMETEK RTC 700B temperature dry-block calibrator which is annually calibrated according to DAkkS-DKD$\mathrm{R}$ 5-4 [16] is used for this purpose. Aside from the verification of the absolute temperature measurement the calibration serves for relative correction of the sensors so that temperature deviations occurring during testing can solely be attributed to the different mounting methods.

As shown by Curtis [17], mechanical stresses induced to the actual sensor wire have an effect on the sensor hysteresis. Since the sensor sheath has to be bent for the clamp-on installation, the influence of mechanical stress of the bending process on the sensor characteristic is studied. To this end, the calibration of PT100 is repeated several times up to $400^{\circ} \mathrm{C}$ with and without mechanical stress and the change in sensitivity of the sensors is observed.

After the first calibration cycle, a deviation of up to $1 \mathrm{~K}$ is observed between the (uncorrected) PT100 and the calibrator reference as shown exemplarily for one sensor in Figure 3 . The polynomial correction function derived on the basis of this data reduces the remaining deviation to below $\pm 0.05 \mathrm{~K}$. For two following testing cycles in the calibrator the polynomial correction function from the first calibration cycle is applied. The sensors show deviations to the calibrator reference within $\pm 0.05 \mathrm{~K}$ as illustrated in Figure 4 for one sensor (according to the observations of [12] and [13]). Prior to a last (4th) testing cycle in the calibrator, the $400 \mathrm{~mm}$ long sensor sheath was bent by $90^{\circ}$ at its centre with a bending radius of $30 \mathrm{~mm}$. 
The application of the correction function from the first cycle, results in a quasi linear increasing underestimation of the actual temperature with a maximum deviation of about $0.18 \mathrm{~K}$ at $400^{\circ} \mathrm{C}$. The described tests were conducted with four different PT100 in total with similar outcome. To avoid such an additional systematic uncertainty, the sensors are brought to the needed shape before their calibration process. Furthermore, a careful treatment of the sensors during transportation and mounting is crucial.

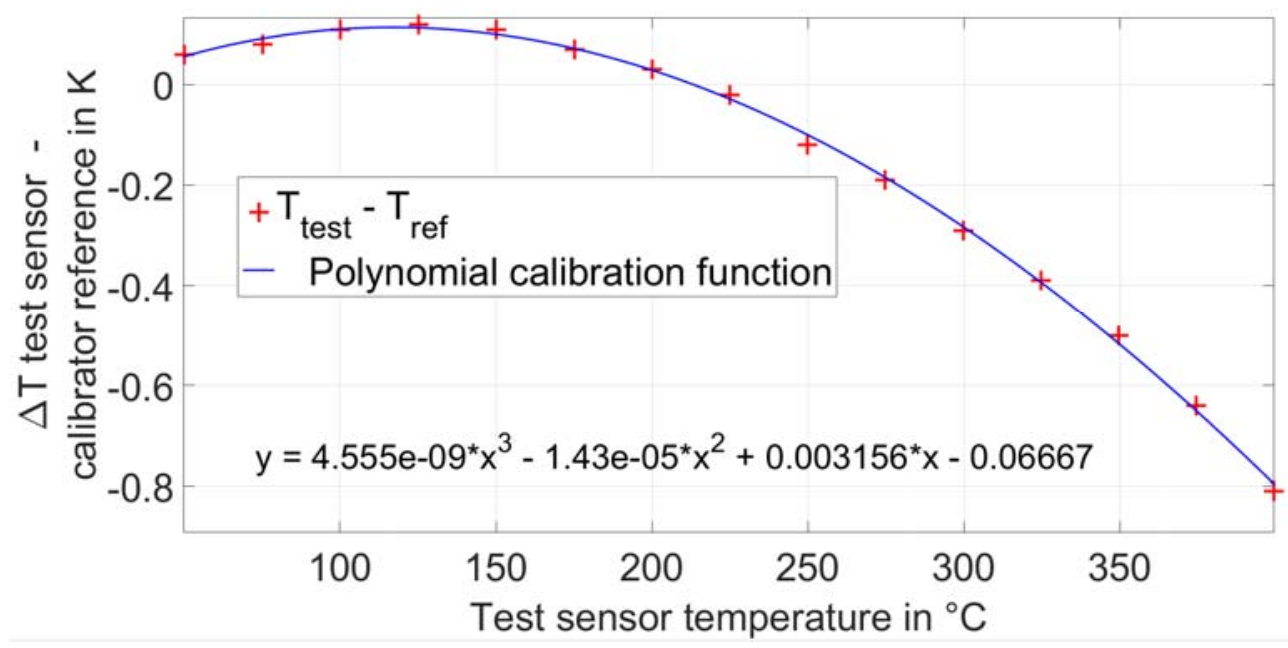

Figure 3: Temperature deviation of test sensors to calibrator reference $\left(1^{\text {st }}\right.$ cycle, calibration)

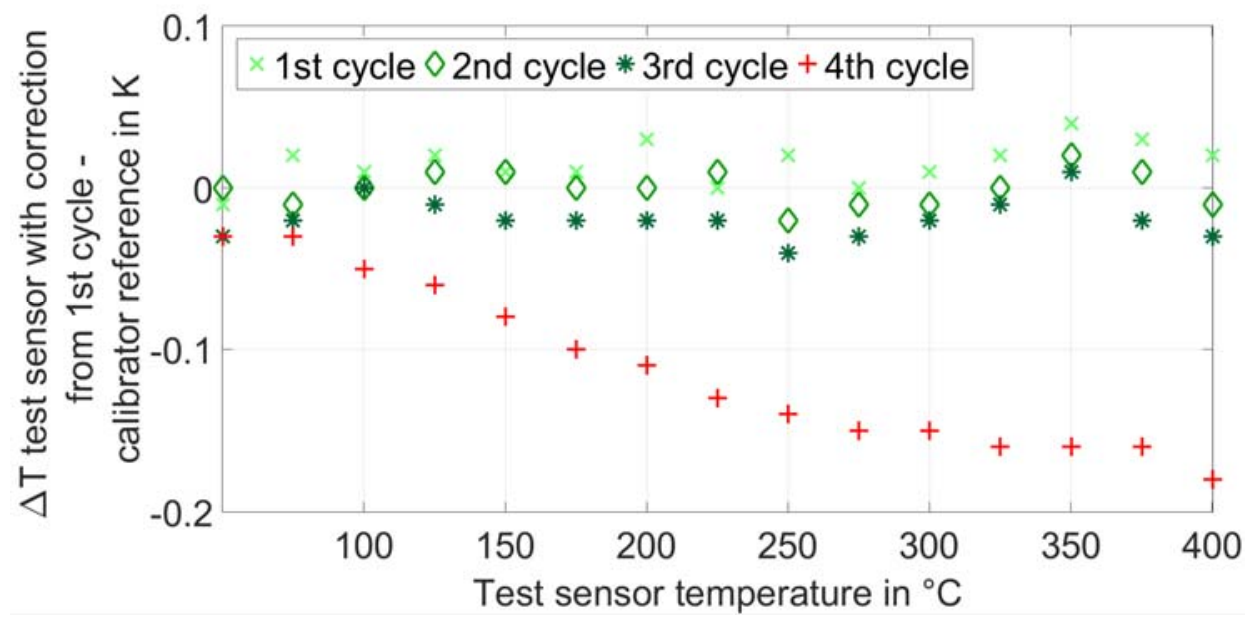

Figure 4: Temperature deviation of a test sensor to the calibrator reference after corrections with polynomials of Figure 3. $2^{\text {nd }}$ and $3^{\text {rd }}$ cycle: with unchanged sensors (no mechanical stress), $4^{\text {th }}$ cycle: after bending (introducing mechanical stress) 
1) Pipe

2) Reference PT100 sensors

3) Clamp-on PT100 sensor with sensor holder

4) Copper temperature shield

5) Insulation

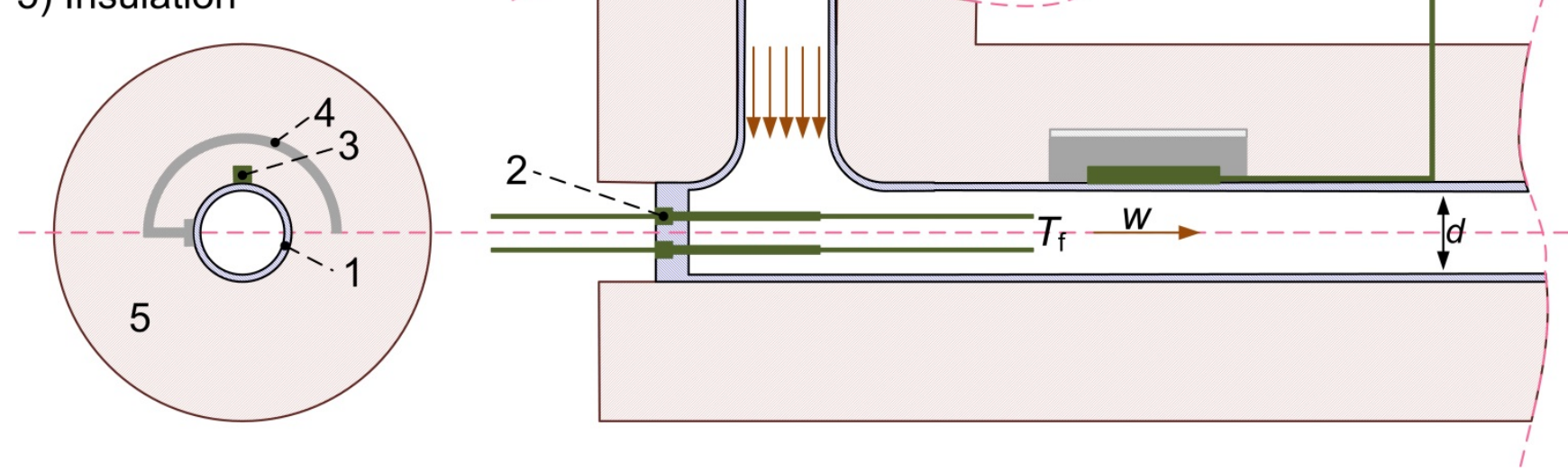

Figure 5: Schematic illustration of clamp on test setup at the KONTAS test facility

\subsection{Qualification setup and instruments}

The detailed study and optimization of the clamp-on temperature setup was carried out using the KONTAS facility. This rotatory parabolic trough test bench is equipped with highly precise measurement equipment and a heating and cooling unit. It is mainly used for the characterization and qualification of CSP components under realistic conditions. The heating and cooling unit with an electrical heating capacity of $54 \mathrm{~kW}$ and a cooling capacity of 100 $\mathrm{kW}$ at $T_{\text {air }}=10^{\circ} \mathrm{C}$, can provide a constant mass flow rate of thermal oil (SYLTHERM800®) between 0.5 and $6 \mathrm{~kg} / \mathrm{s}$ at temperatures up to $400^{\circ} \mathrm{C}$. The outlet temperature of the heating cooling unit can be controlled within $< \pm 0.1^{\circ} \mathrm{C}[18]$.

Temperature signals are logged via mobile Almemo® 2890-9 loggers from Ahlborn. Process variables which are relevant to the operation of the KONTAS test facility and data of the meteorological station, are recorded by a Gantner e.bloxx data acquisition system.

The present tests are carried out at a bypass of the test facility, which runs parallel to the solar collector (no solar influence on fluid temperature). The wetted inline sensors are mounted with compression fittings inside a three inch pipe, immediately upstream of the clamp-on sensors (distance below $1 \mathrm{~m}$ ). The clamp-on sensors are inserted into drillings of sensor holders. These sensor holders consist of brass blocks, which homogenize the temperatures in the immediate surrounding of the sensors with the dimensions $10 \mathrm{~mm}$ width, $10 \mathrm{~mm}$ height and $60 \mathrm{~mm}$ depth. The contact surfaces of the brass blocks correspond to the pipe radius. Drillings for sensors are positioned as close as possible to the contact surfaces (distance $<1 \mathrm{~mm}$ ) and have a total depth of $50 \mathrm{~mm}$. The sensor holders are clamped to the pipe using hose clamps (torque of about $5 \mathrm{Nm}$ ) with thermal grease for a better thermal coupling. To reduce the ambient influences on the clamp-on sensors, temperature shields are clamped around them, as illustrated in Figure 5. These temperature shields consist of a copper halfpipe for each sensor (wall thickness of $2 \mathrm{~mm}$ ), which is thermally coupled to the pipe conducting heat around the clamped sensor and thus reducing the temperature gradient 
in this zone. The free space between shield and sensor holder is filled with insulation material. The entire surroundings of the measurement location are insulated (wall thickness of the insulation $75 \mathrm{~mm}$ ). A series of measurements is conducted to identify the influence of the insulation and the temperature shield at the temperature difference between embedded and clamp-on sensors. Each measurement point represents the average values over a longer testing time (10 to 30 minutes). During the measurement recording ambient and facility operating conditions are monitored. Measurement points with a standard deviation $\geq 0.1^{\circ} \mathrm{C}$ are rejected. All measurements are carried out redundantly with at least two sensors for each measured variable.

\subsubsection{Effect of insulation}

As expected, proper insulation of the clamp-on measurement setup is of upmost importance. The influence of the insulation is illustrated in Figure 6. Already at comparatively low fluid temperatures around $100^{\circ} \mathrm{C}$ and wind speeds below $2 \mathrm{~m} / \mathrm{s}$ the temperature difference between inline reference and clamp-on measurement reaches around $0.6 \mathrm{~K}$. This temperature difference increases with the absolute fluid temperature and reaches values around $1.2 \mathrm{~K}$ above the insulated measurement setup at fluid temperatures around $350^{\circ} \mathrm{C}$.

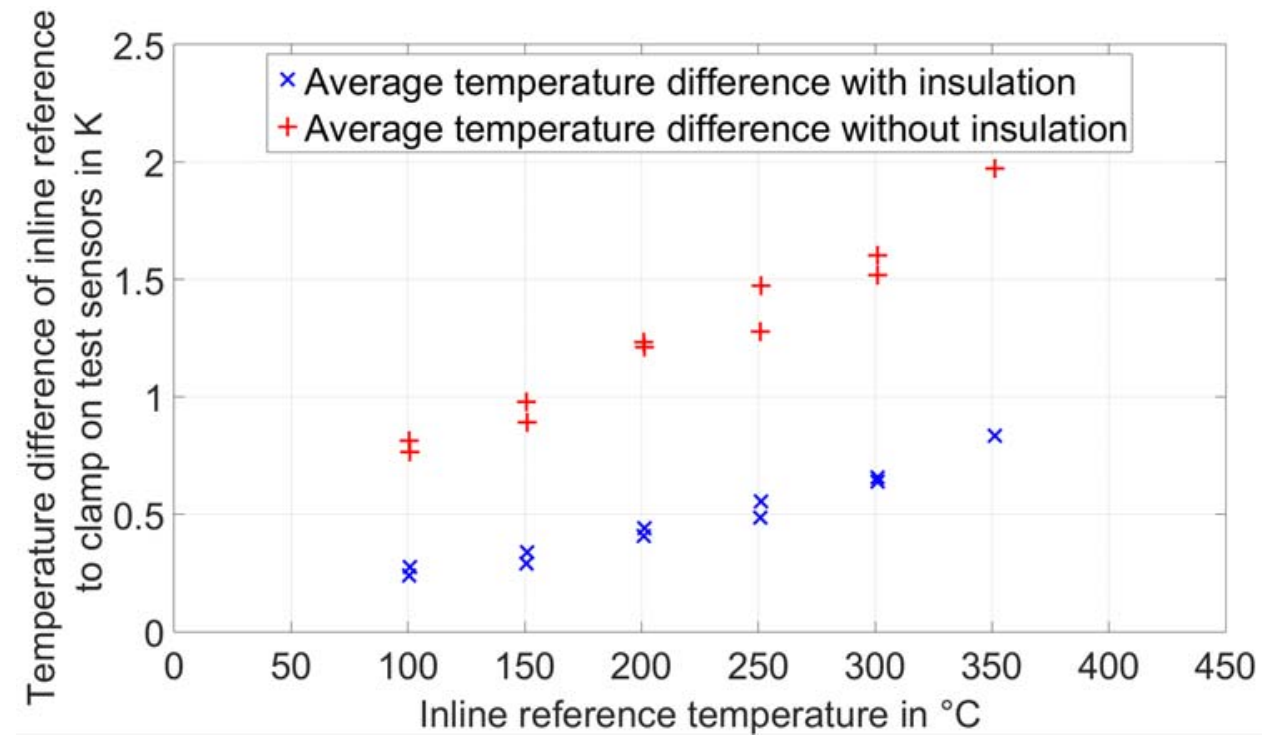

Figure 6: Influence of thermal insulation on clamp-on measurement method as a function of fluid temperature

\subsubsection{Effect of shield}

Tests of the clamp-on temperature measurement system with and without the temperature shield mounted are conducted to study its effect on the temperature difference between fluid and sensor temperature.

Figure 7 shows a reduction of the difference between fluid and sensor temperature by approximately $0.2^{\circ} \mathrm{K}$ at $390^{\circ} \mathrm{C}$ with the temperature shield. However, there is still a remaining temperature difference between fluid and sensor of between 0.4 and $0.9^{\circ} \mathrm{K}$ in the temperature range between 200 and $390^{\circ} \mathrm{C}$. This difference has to be corrected, depending on the flow conditions. 


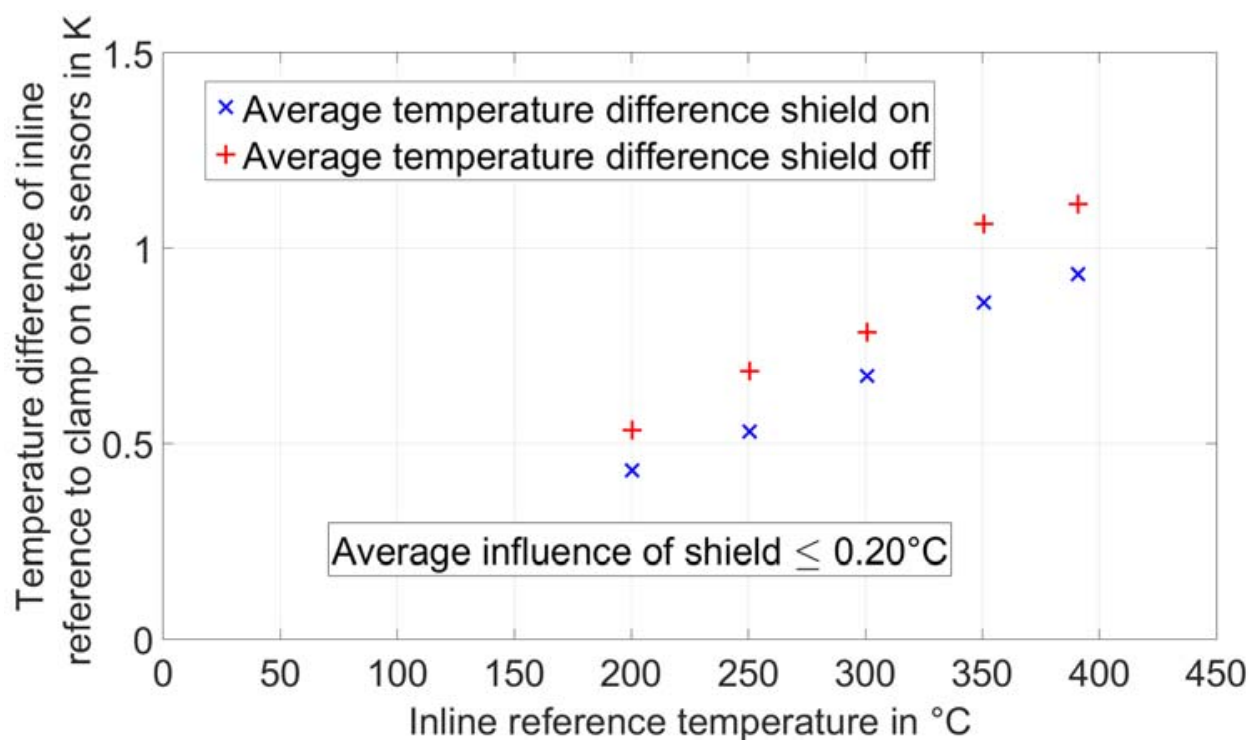

Figure 7: Influence of temperature shields on clamp-on measurement method

\subsubsection{Influence of external conditions}

All measurements were conducted during daytime with wind speeds up to $4 \mathrm{~m} / \mathrm{s}$ and ambient temperatures down to $20^{\circ} \mathrm{C}$. The total heat flow from the fluid to the environment can be described by a convective and radiative part.

The influence of convective losses on the measurement is investigated for three cases (see Table 2), using the heat transfer model which will be presented in section 5.1. As expected, the wind speed has only a minor influence on the insulated measuring system. The deviations of the sensor temperature seen in Table 2 due to the different wind speeds are below $0.1 \mathrm{~K}$ and are well within the spread of the observed measurements presented in section 4.

Table 2: Wind speed near piping, Reynolds number for external air flow $\mathbf{R e}_{\text {air }}$, heat transfer coefficient $h_{\text {air }}$ for external flow and expected sensor temperature $T_{\text {co }}$ (fluid temperature $390^{\circ} \mathrm{C}$, mass flow rate $6 \mathrm{~kg} / \mathrm{s}$ )

\begin{tabular}{l|ccc}
\hline Wind speed in $\mathrm{m} / \mathrm{s}$ & 1 & 4 & 10 \\
\hline $\mathrm{Re}_{\text {air }}$ & 21550 & 86200 & 215500 \\
\hline$h_{\text {air }}$ in $\mathrm{W} /\left(\mathrm{m}^{2} \mathrm{~K}\right)$ & 11.6 & 34.1 & 69.8 \\
\hline$T_{\text {co }}$ in ${ }^{\circ} \mathrm{C}$ & 388.84 & 388.76 & 388.74 \\
\hline
\end{tabular}

The wind speed has already a negligible effect on the sensor temperature. The radiation losses from the insulation to the surrounding sky and ground are one order of magnitude smaller than the convective losses and hence are neglected in the model. This simplification has been investigated by using measured pyrgeometer data for various tests, calculating the sky temperature according to [19] and calculating the radiative losses by the cylindrical aluminum protecting sheet of the insulation radiating to the sky. This is a conservative approach which overestimates the radiative flow because the emitting surface area is directed both to the sky and the usually hotter ground. For small wind speeds between 1 and $2 \mathrm{~m} / \mathrm{s}$, and for sky temperatures between 7 and $14^{\circ} \mathrm{C}$, the radiative flow never was higher 
than one tenth of the convective flow. The effect on the sensor temperature is in the order of some hundredth of Kelvin.

\subsubsection{Influence of the Reynolds number on temperature difference between reference PT100 sensors and clamp-on sensors}

Due to the positively correlated relationship between the heat transfer coefficient and Reynolds number, it can be expected that the temperature difference between embedded and clamp-on sensors rises with constant absolute fluid temperature but dropping Reynolds number (reduction of mass flow rate). The influence of the Reynolds number is estimated by a heat transfer model (see section 5.1). The resulting estimated clamp-on sensor temperatures are experimentally confirmed with the calculated values averaging $0.1^{\circ} \mathrm{K}$ above the measured values, with the same tendency (see Figure 8).

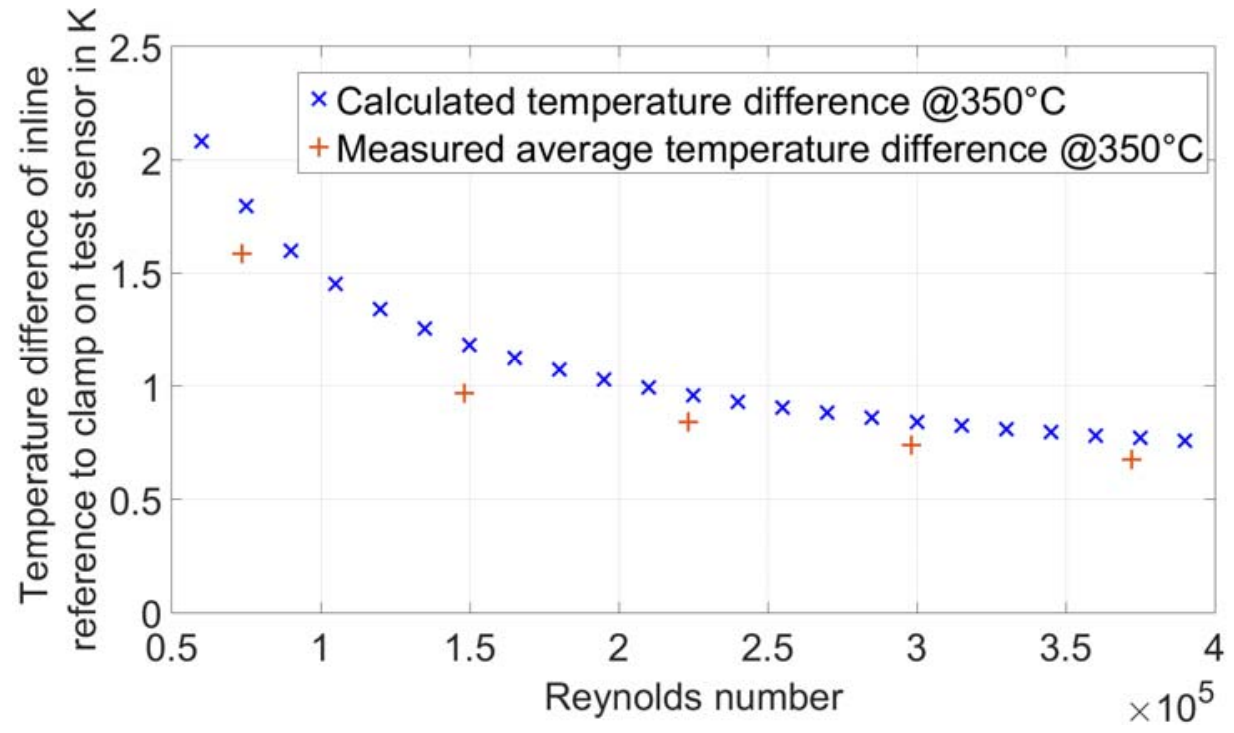

Figure 8: Measured and calculated influence of Reynolds number on temperature deviation between fluid and sensor temperature for clamp-on system (exemplarily for $T_{\mathrm{f}}=350^{\circ} \mathrm{C}$ )

\section{Clamp-on correction for CSP applications with thermal oil}

The aim of clamp-on systems is to determine the fluid temperature while measuring on the external pipe surface. Therefore, an empirical temperature gradient correction accounting for the temperature gradient as shown in Figure 10 is required. In order to reduce the influence of the Reynolds number on the characterization and correction of the clamp-on sensors for CSP applications (see Figure 8), temperature-dependent lower limits for the Reynolds number are defined (see Table 3).

Table 3: Minimum Reynolds numbers for sensor characterization as a function of fluid temperature investigated experimentally in this paper

\begin{tabular}{l|lllllll}
\hline$T\left[{ }^{\circ} \mathrm{C}\right]$ & 100 & 150 & 200 & 250 & 300 & 350 & 390 \\
\hline Minimum Re & $3 \mathrm{e} 4$ & $5 \mathrm{e} 4$ & $7 \mathrm{e} 4$ & $1 \mathrm{e} 5$ & $1.5 \mathrm{e} 5$ & $2 \mathrm{e} 5$ & $2 \mathrm{e} 5$ \\
\hline
\end{tabular}

Over 10 months, a total of 73 measurement points with fluid temperatures between $100^{\circ} \mathrm{C}$ and approximately $400^{\circ} \mathrm{C}$ are recorded. Each measurement point consists of 10 to 30 minutes of stable data with a standard deviation below $0.1^{\circ} \mathrm{C}$. The data time resolution is 
one value per second. Wind speeds of $4 \mathrm{~m} / \mathrm{s}$ at the measurement position are not exceeded. The ambient temperatures range in between $20^{\circ} \mathrm{C}$ and $30^{\circ} \mathrm{C}$. During this 10 month measurement period, the test setup has been repeatedly dismantled and mounted. Figure 9 illustrates that the measurements achieve reproducible temperature differences between embedded and clamp-on sensors, increasing with the fluid temperature. The observed spread of the measured temperature difference shown in Figure 9 is $0.26 \mathrm{~K}$ at a fluid temperature of approx. $100^{\circ} \mathrm{C}$ and $0.4 \mathrm{~K}$ at a fluid temperature of approx. $390^{\circ} \mathrm{C}$. Conceivable causes for this spread are varying clamping force of the sensor holder on the pipe, varying quality of insulation around the clamp-on system, different ambient conditions and PT100 hysteresis. A polynomial correction function $\Delta T_{\mathrm{f}-\mathrm{co}}$ is generated from the measurement data, which adjusts the clamp-on surface temperature $T_{\text {co }}$ to the approximate fluid temperature $T_{\mathrm{co}, \mathrm{f}}$ :

$T_{\text {co,f }}=T_{\text {co }}+\Delta T_{\mathrm{f}-\text { co }}$

$\Delta T_{\mathrm{f}-\text { co }}=3.84 \cdot 10^{-6} \frac{K}{{ }^{o} C^{2}} \cdot T_{\text {co }}^{2}+6.676 \cdot 10^{-4} \frac{K}{{ }^{o} \mathrm{C}} \cdot T_{\text {co }}+1.36 \cdot 10^{-1} \mathrm{~K}$

Equation 1

Equation 2

This function is applicable for the presented clamp-on system mounted on pipes with thermal oils like Syltherm-800 or VP1, 3 inch pipes, wall thickness around $6 \mathrm{~mm}$, mass flow rates $\geq 3$ $\mathrm{kg} / \mathrm{s}$, and $\operatorname{Re}$ numbers as indicated in Table 4. These conditions usually are found in parabolic trough CSP plants with current EuroTrough [9] collector loop piping.

The observed spread is considered later in the uncertainty analysis of the corrected clamp-on measurements.

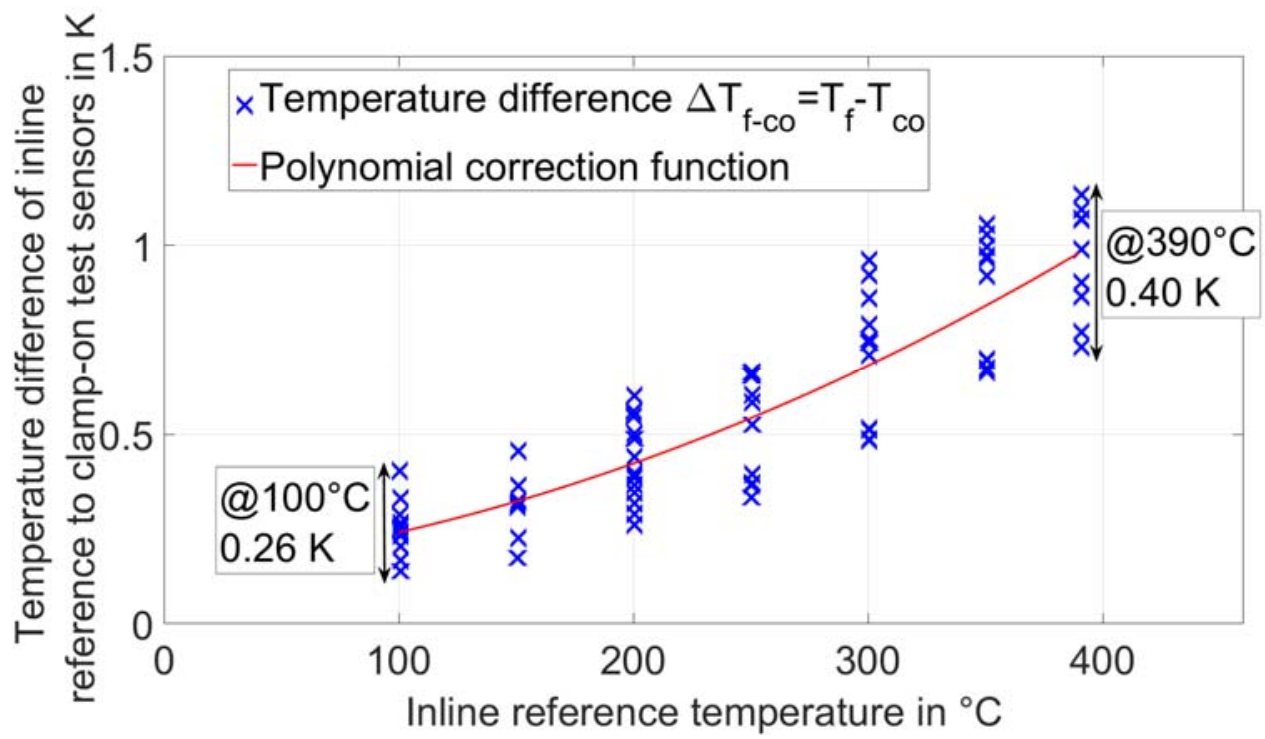

Figure 9: Resulting temperature deviation of the clamp-on measurement system as a function of the absolute HTF temperature for typical conditions of a parabolic trough CSP plant.

Table 4 lists the results of measurements, which are not used for the generation of the correction function. It shows that temperature deviations of embedded and corrected clampon sensors are within the uncertainties of the measurements. The resulting uncertainty of the clamp-on measurements at a fluid temperature of $390^{\circ} \mathrm{C}$ is below $\pm 0.7 \mathrm{~K}(2 \sigma)$. 
Table 4: Comparison of embedded to clamp-on sensors after polynomial correction with respective uncertainties

\begin{tabular}{ccccc}
$\begin{array}{c}\text { Reference fluid } \\
\text { temperature } T_{\mathrm{f}}\end{array}$ & $\mathrm{U}\left(T_{\mathrm{f}}\right)(2 \sigma)$ & $\begin{array}{c}\text { Corrected clamp-on } \\
\text { temperature } T_{\text {co,f }}\end{array}$ & $\mathrm{U}\left(T_{\text {co,f }}\right)(2 \sigma)$ & $T_{\mathrm{f}}-T_{\text {co,f }}$ \\
\hline $100.67^{\circ} \mathrm{C}$ & $\pm 0.16^{\circ} \mathrm{C}$ & $100.72^{\circ} \mathrm{C}$ & $\pm 0.34^{\circ} \mathrm{C}$ & $-0.05 \mathrm{~K}$ \\
$150.83^{\circ} \mathrm{C}$ & $\pm 0.18^{\circ} \mathrm{C}$ & $150.61^{\circ} \mathrm{C}$ & $\pm 0.43^{\circ} \mathrm{C}$ & $0.22 \mathrm{~K}$ \\
$200.45^{\circ} \mathrm{C}$ & $\pm 0.21^{\circ} \mathrm{C}$ & $200.19^{\circ} \mathrm{C}$ & $\pm 0.49{ }^{\circ} \mathrm{C}$ & $0.26 \mathrm{~K}$ \\
$250.52^{\circ} \mathrm{C}$ & $\pm 0.26^{\circ} \mathrm{C}$ & $250.22^{\circ} \mathrm{C}$ & $\pm 0.50^{\circ} \mathrm{C}$ & $0.31 \mathrm{~K}$ \\
$300.58^{\circ} \mathrm{C}$ & $\pm 0.28^{\circ} \mathrm{C}$ & $300.81^{\circ} \mathrm{C}$ & $\pm 0.54^{\circ} \mathrm{C}$ & $-0.23 \mathrm{~K}$ \\
$350.78^{\circ} \mathrm{C}$ & $\pm 0.31^{\circ} \mathrm{C}$ & $350.55^{\circ} \mathrm{C}$ & $\pm 0.60^{\circ} \mathrm{C}$ & $0.23 \mathrm{~K}$ \\
$390.95^{\circ} \mathrm{C}$ & $\pm 0.33^{\circ} \mathrm{C}$ & $390.78^{\circ} \mathrm{C}$ & $\pm 0.62^{\circ} \mathrm{C}$ & $0.17 \mathrm{~K}$ \\
\hline
\end{tabular}

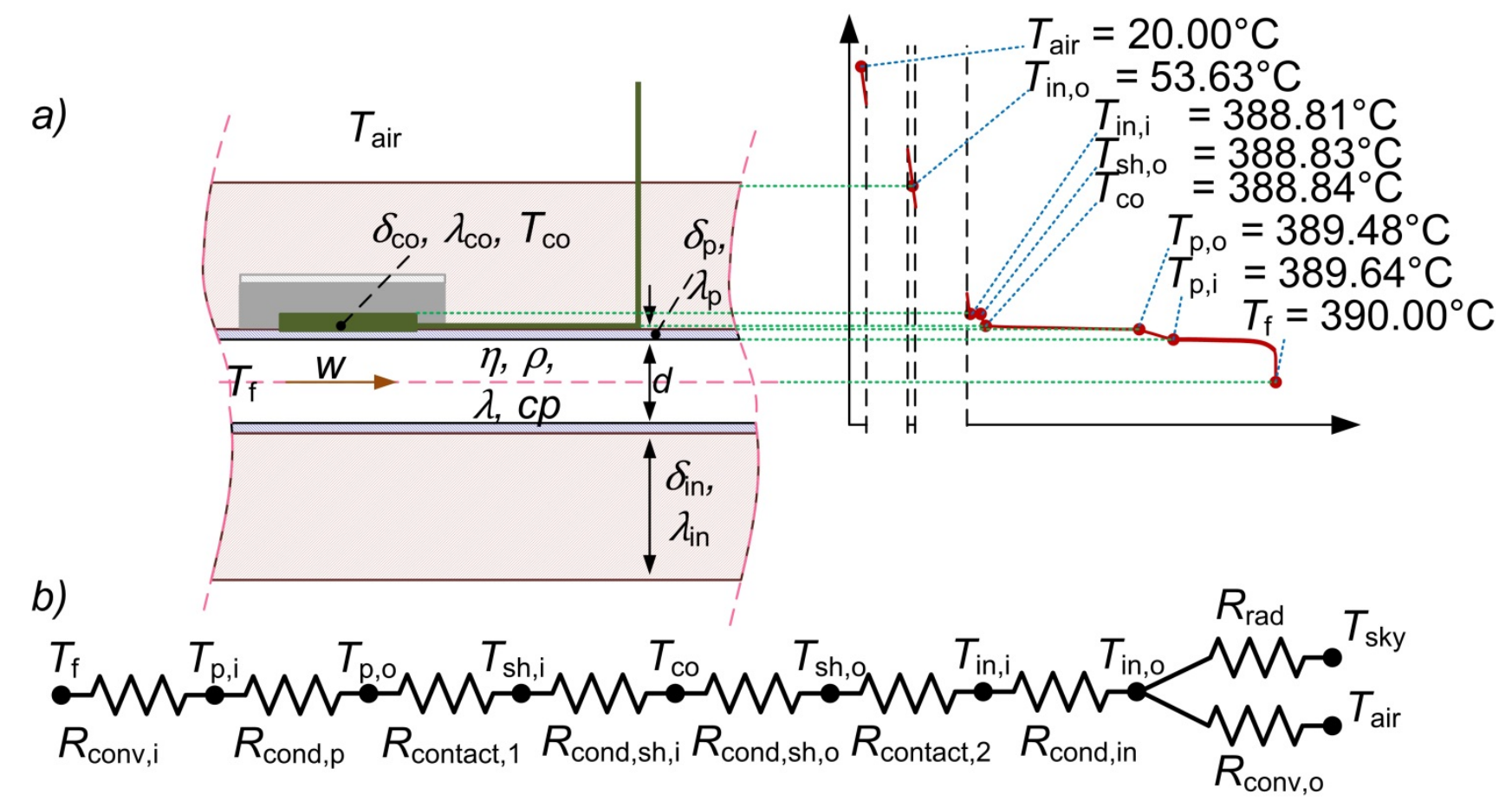

Figure 10: Temperature gradient of clamp-on test setup from fluid to ambient conditions of an exemplary measurement point at the KONTAS test facility (wind speed of $1 \mathrm{~m} / \mathrm{s}$ and mass flow of $6 \mathrm{~kg} / \mathrm{s}$ ). (a) Simplified sketch with the most important temperatures. (b) thermal equivalent circuit describing the heat transfer steps;

\section{Clamp-on correction for general applications via dimensional analysis}

A wider range of clamp-on applications with different HTFs, pipe geometries and operating conditions is of general interest. This section broadens the application of the correction function by running a huge amount of simulation studies an experimentally validated heat transfer model and deriving an easy applicable dimensionless correction equation for the temperature correction. The temperature gradient from the fluid to the outer surface of the 
insulation for an exemplary measurement point, at a fluid temperature of $390^{\circ} \mathrm{C}$ and ambient temperature of $20^{\circ} \mathrm{C}$ is illustrated in Figure 10.

\subsection{Modeling of heat transfer}

The convective heat transfer correlation based on a heat transfer approach for pipes from Gnielinski [20] is used:

$N u_{i}=\frac{(\xi / 8) \operatorname{RePr}}{1+12.7 \sqrt{\xi / 8\left(\operatorname{Pr}^{2 / 3}-1\right)}}\left[1+\left(d_{i} / l\right)^{2 / 3}\right]$

Equation 3

with

$\xi=\left(1.8 \log _{10} R e-1.5\right)^{-2}$

Equation 4

The average Nusselt number in cross-flow over tubes is calculated as suggested by Gnielinski [21] and used for the heat transfer model for the outer convective heat transfer from the insulation to ambient air. The thermal resistance at the interface of the HTF to the pipe and the insulation to the ambient air dominated by convection is calculated by

$R_{\mathrm{conv}, \mathrm{j}}=\frac{1}{N u_{\mathrm{j}} \cdot \lambda \cdot \pi}$

Equation 5

The conductive thermal resistance in each layer $j$ (thermal conduction through pipe wall, inner sensor holder to sensor, sensor to outer sensor holder and insulation) is calculated by

$R_{\text {cond }, \mathrm{j}}=\frac{1}{2 \pi \cdot \lambda_{\mathrm{j}}} \ln \left(\frac{d_{\mathrm{o}, \mathrm{j}}}{d_{\mathrm{i}, \mathrm{j}}}\right)$

Equation 6

The thermal resistance between the pipe and the sensor holder $R_{\text {contact, } 1}$ is determined through an iterative process by using the measured temperature difference between clamp on sensor and fluid temperature shown in Figure 9 and the known other thermal resistances. The good repeatability achieved during the test campaigns indicates that under the application of the developed mounting procedure, there are no major fluctuations of the thermal resistance. By iterative variation of the contact resistance while minimizing the deviation between modeled and measured temperature difference, $R_{\text {contact, } 1}=0.0025 \mathrm{Km} / \mathrm{W}$ was found.

The contact resistance between sensor holder and the insulation $R_{\text {contact,2 }}$ is much smaller than the resistance of the insulation $R_{\text {cond,in }}$ and hence is neglected. This simplification has minor influence on the uncertainty of the correction, because the simplification is made outside the interesting temperature gradient.

Due to the precise fitting between the sensor holder and sensor and the use of high temperature-resistant thermal grease, no significant contact resistant inside the sensor holder is present.

The total heat flow is calculated according to Equation 7.

$\dot{q}^{\prime}=\frac{1}{\sum_{i=1}^{7} R_{i}}\left(T_{\mathrm{f}}-T_{\mathrm{amb}}\right)$

Equation 7

The temperatures at the layer boundaries (see equivalent diagram Figure 10) are calculated using the thermal resistance of a neighboring layer according to Equation 8. 
The empirically determined influence of the temperature shields, see Figure 7 , is considered as a subsequent correction.

\subsection{Dimensional analysis}

For operating conditions, geometries or material properties that do not fully match the case described in sections 2 and 4, a more general approach is needed for the approximation of the temperature gradient between fluid and clamp-on sensor. To this end, a virtual data space containing calculated reference temperature profiles is generated using the model of section 5.1. This space covers a wide variety of application cases. By means of a dimensional analysis a parameterized correction model function is created. The parameters of this model function are then fitted to the virtual data space.

A dimensional analysis is a method which identifies the independent physical quantities with the associated fundamental dimensions for a physical problem and describes it in a simplified dimensionless functional approach. Thus, it simplifies tasks by reducing the number of variables that must be specified. The dimensionless function has to be expressed in a form, in which the relationships among the actual physical quantities remain valid, regardless of the base units' magnitudes [22].

In the present case, there is a global temperature gradient between fluid temperature and ambient temperature $\left(\Delta T_{\text {f-air }}=T_{\mathrm{f}}-T_{\text {air }}\right)$. Within this temperature gradient the actual target is the temperature gradient between fluid temperature and clamp-on sensor temperature $\left(\Delta T_{\mathrm{f}-\mathrm{co}}=T_{\mathrm{f}}-T_{\mathrm{co}}\right)$.

The flow through the pipe is described by the flow velocity $w$, the inner pipe diameter $d$, the fluid density $\rho$ and the fluid dynamic viscosity $\eta$. Relevant quantities for the convective heat transfer are the specific heat capacity $c_{p}$ and the thermal conductivity $\lambda$. The pipe and insulation dimensions and properties are described by the wall (insulation) thickness $\delta_{\mathrm{p}}\left(\delta_{\text {in }}\right)$ and the thermal conductivity of the used materials $\lambda_{p}\left(\lambda_{i n}\right)$. Ambient conditions are described by an ambient heat transfer coefficient $h_{\text {air. }}$. The geometries of the sensor holders, sensors and temperature shields as well the contact pressure and radiation boundary condition are assumed to be constant and the same as described in sections 3 and 4 . Thus, there are 13 variable quantities which can be described by the four fundamental dimensions mass in $\mathrm{kg}$, length in $\mathrm{m}$, time in $\mathrm{s}$ and temperature in $\mathrm{K}$. According to the Buckingham $\pi$-theorem, having $n=13$ independent variables and $k=4$ fundamental dimensions, we need $\pi=n-k=9$ dimensionless variables to simplify the present physical problem [23]. Table 5 lists dimensionless variables and their mathematical definition resulting from the dimensional analysis. 
Table 5: Dimensionless variables for dimensional analysis

\begin{tabular}{|c|c|c|}
\hline & Notation & Mathematical function \\
\hline $\begin{array}{l}\pi \\
1\end{array}$ & Reynolds number & $R e=\frac{w d \rho}{\eta}$ \\
\hline $\begin{array}{l}\pi \\
2\end{array}$ & Prandtl number & $\operatorname{Pr}=\frac{\eta c_{\mathrm{p}}}{\lambda}$ \\
\hline $\begin{array}{l}\pi \\
3\end{array}$ & $\begin{array}{l}\text { Dimensionless temperature gradient } \\
\text { fluid and ambient }\end{array}$ & $\Delta \Theta_{\mathrm{f}-\mathrm{air}}=\Delta T_{\mathrm{f}-\mathrm{air}} c_{\mathrm{p}}^{3} d^{2} \rho^{2} / \lambda^{2}$ \\
\hline $\begin{array}{l}\pi \\
4\end{array}$ & $\begin{array}{l}\text { Dimensionless temperature gradient } \\
\text { fluid and sensor }\end{array}$ & $\Delta \Theta_{\mathrm{f}-\mathrm{co}}=\Delta T_{\mathrm{f}-\mathrm{co}} c_{\mathrm{p}}^{3} d^{2} \rho^{2} / \lambda^{2}$ \\
\hline $\begin{array}{l}\pi \\
5\end{array}$ & Biot number & $B i=\frac{h_{\mathrm{air}} \delta_{\mathrm{in}}}{\lambda_{\mathrm{in}}}$ \\
\hline $\begin{array}{l}\pi \\
6\end{array}$ & $\begin{array}{l}\text { Thermal conductivity ratio pipe to } \\
\text { fluid }\end{array}$ & $\frac{\lambda_{\mathrm{p}}}{\lambda}$ \\
\hline $\begin{array}{l}\pi \\
7\end{array}$ & $\begin{array}{l}\text { Thermal conductivity ratio insulation } \\
\text { to fluid }\end{array}$ & $\frac{\lambda_{\text {in }}}{\lambda}$ \\
\hline $\begin{array}{l}\pi \\
8\end{array}$ & Dimensionless pipe wall thickness & $\frac{\delta_{p}}{\delta}$ \\
\hline $\begin{array}{l}\pi \\
9\end{array}$ & $\begin{array}{l}\text { Dimensionless insulation wall } \\
\text { thickness }\end{array}$ & $\frac{\delta_{\text {in }}}{\delta}$ \\
\hline
\end{tabular}

The unknown dimensionless temperature gradient between fluid and sensor can be described by

$\Delta \Theta_{f-c o}=f\left(\begin{array}{c}R e, \operatorname{Pr}, \Delta \Theta_{\mathrm{f}-\mathrm{air}}, B i, \\ \lambda_{\mathrm{p}} / \lambda, \lambda_{\mathrm{in}} / \lambda, \delta_{\mathrm{p}} / d, \delta_{\mathrm{in}} / d\end{array}\right)$

Equation 9

\subsection{Correction function}

The general correlation of Equation 9 is transformed to a parameterized correction function. Several correction functions with different numbers of parameters are checked. A correction function having a reasonable number of parameters and still providing good results is:

$$
\begin{aligned}
& \Delta \Theta_{\mathrm{f}-\text { co }}=a_{1}(R e+d m)^{m}(P r+d n)^{n} \\
& \left(\Delta \Theta_{\mathrm{f}-\mathrm{air}}\right)^{p}(B i+d q)^{q}\left(\lambda_{\mathrm{p}} / \lambda\right)^{r}\left(\lambda_{\text {in }} / \lambda\right)^{s} \\
& \left(\delta_{\mathrm{p}} / d\right)^{u}\left(\delta_{\text {in }} / d+d v\right)^{v}
\end{aligned}
$$

Equation 10

To fit the 13 parameters $\left(a_{1}, d m, m, d n, n, p, d q, q, r, s, u, d v\right.$ and $\left.v\right)$ of Equation 10 to a wide range of applications, a plausible virtual space containing 13 quantities is created by simulation. The 12 input parameters shown in Table 6 are varied within their respective ranges and the temperature difference between fluid temperature and clamp-on sensor temperature $\left(\Delta T_{\mathrm{f}-\mathrm{co}}\right)$ is calculated using the equations of section 5.1 .

A total of $1,400,000$ samples is created with the Latin hypercube sampling (LHS) method. The LHS method takes randomly independent samples which recreate the input distribution by stratification of an input distribution [24]. In our case we used a uniform distribution. The 12 variables and their used ranges are stated in Table 6 . Not all 1,400,000 samples produced 
physically reasonable combinations of the variables. After filtration of unrealistic samples, 145'552 samples were used to fit Equation 10.

Table 6: Range of virtual data space used as input for parameter estimation of Equation 10

\begin{tabular}{|l|c|c|}
\hline Parameter & Min value & Max value \\
\hline$R e$ & 30,000 & $1,000,000$ \\
\hline$P r$ & 0.1 & 1000.0 \\
\hline$\Delta \Theta_{\mathrm{f}-\text { air }}$ & $4.63 \mathrm{E}+13$ & $9.24 \mathrm{E}+17$ \\
\hline$B i$ & 1 & 200 \\
\hline$\lambda_{\mathrm{p}} / \lambda$ & 80 & 1450 \\
\hline$\lambda_{\text {in }} / \lambda$ & 0.3 & 2,0 \\
\hline$\delta_{p} / \delta$ & 0.05 & 0.18 \\
\hline$\delta_{\text {in }} / \delta$ & 0.5 & 12.0 \\
\hline$c_{\mathrm{p}}[\mathrm{J} /(\mathrm{kgK})]$ & 1780 & 5000 \\
\hline$\lambda[\mathrm{W} /(\mathrm{mK})]$ & 0.064 & 0.150 \\
\hline$\rho\left[\mathrm{kg} / \mathrm{m}^{3}\right]$ & 555 & 1045 \\
\hline$d[\mathrm{~m}]$ & 0.025 & 0.200 \\
\hline
\end{tabular}

The iterative algorithm BOBYQA (Bound Optimization BY Quadratic Approximation), based on quadratic approximations is used to find the least value of the Equation 10 by optimizing the 13 parameters. BOBYQA uses quadratic approximations $Q$ to $F$ with $F$ being the objective function (Equation 10) that satisfies $Q_{k}\left(y_{j}\right)=F\left(y_{j}\right)$, where the interpolation points $y_{\mathrm{j}}$ are chosen and adjusted automatically [25]. Objective values $\Delta \Theta_{f-c o}$ were taken from the virtual data space. The determined parameters of the correction function are listed in Table 7.

Table 7: Optimized parameters for least value of Equation 10

\begin{tabular}{|l|l|l|l|l|l|}
\hline & $a_{1}$ & $d m$ & $d n$ & $d q$ & $d v$ \\
\hline Value & 2.05215 & -13470 & 0.94623 & 0.58544 & 1.47963 \\
\hline
\end{tabular}

\begin{tabular}{|l|l|l|l|l|l|l|l|l|}
\hline & $m$ & $n$ & $p$ & $q$ & $r$ & $s$ & $u$ & $v$ \\
\hline Value & -0.37840 & -0.20070 & 0.98186 & 0.04119 & -0.12568 & 0.98235 & 0.20431 & -0.42682 \\
\hline
\end{tabular}

\subsection{Quality check}

The quality of the resulting correction function (Equation 10 and parameters of Table 7) is checked by comparing the temperature gradient predicted by the correction function with the values generated by the model equations of section 5.1. Using all virtual data samples, the deviations lie within $\pm 0.04 \mathrm{~K}$ in $95.5 \%$ of the cases (see Figure 11). In only $0.08 \%$ of the cases deviations over $\pm 0.4 \mathrm{~K}$ are observed. Hence, the quality of the general correction function is good. 


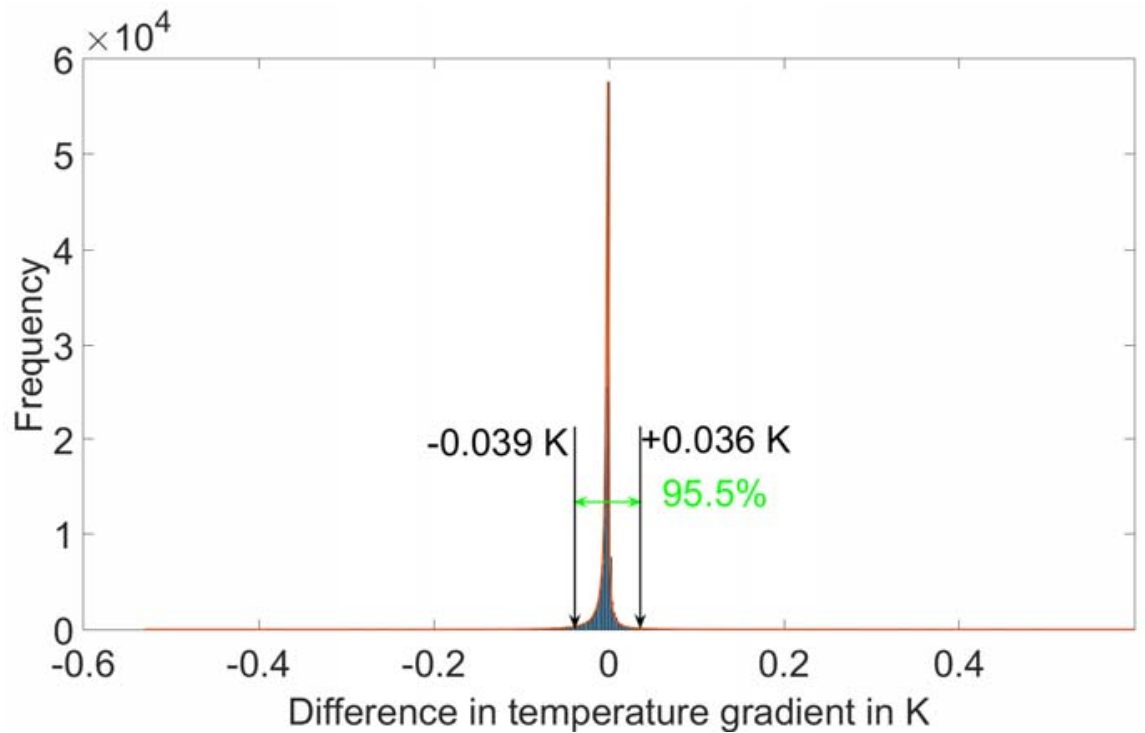

Figure 11: Histogram of the deviation in temperature gradient between values generated by the derived correction function (Equation 10 and Table 7) and the model equations of section 5.1.

Figure 12 shows the ability of the derived correction function to correct temperature readings of the clamp-on measurement system with good quality. The underlying measurement data (round filled markers) are results of the experiments performed with the HTF Syltherm-800 presented in sections 3 and 4 . The temperature gradient between fluid temperature and clamp-on sensor temperature $\Delta T_{\mathrm{f}-\mathrm{co}}$ is plotted versus the fluid temperature $T_{\mathrm{f}}$ measured by wetted sensors in the pipe. As shown before, the temperature gradient increases with increasing fluid temperature. The plot shows that both the model equations of section 5.1 (cross markers) and the fitted correction function, Equation 10 and Table 7, (squared markers) predict the temperature difference with good quality. The deviations between the measured temperature gradient and the fitted correction function are below $0.1 \mathrm{~K}$ with a RMSD of about $0.08 \mathrm{~K}$.

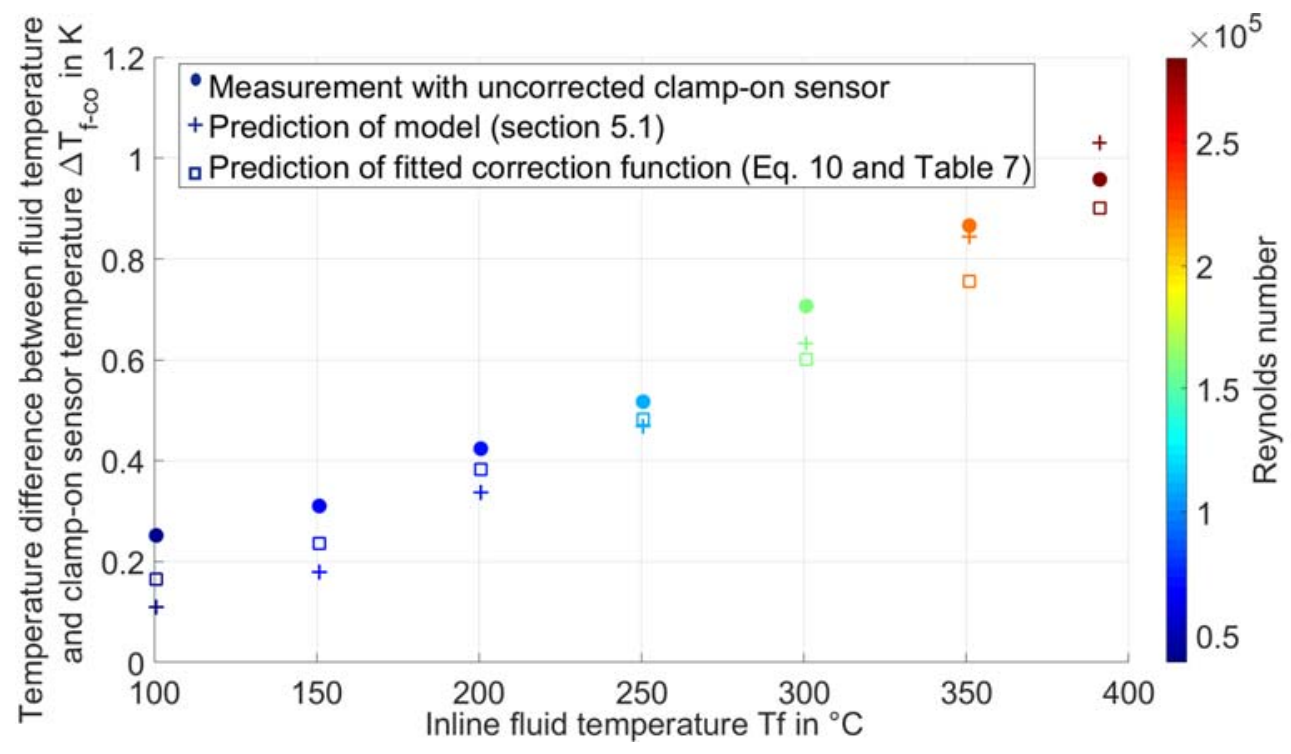

Figure 12: Comparison of the predictions of the fitted correction function Equation 10 and the model of section 5, and measurements with the uncorrected clamp-on sensor (Syltherm-800, $T_{\text {air: }}: 20$ to $30^{\circ} \mathrm{C}, h_{\text {air }}$ : 6.5 to $26.3 \mathrm{~W} /\left(\mathrm{m}^{2} \mathrm{~K}\right)$; clamp-on geometry and materials as in section 3$)$ : 


\section{Industrial experience in a commercial solar power plant}

The clamp-on temperature measurement system was used during a field measurement campaign for performance measurements of three different parabolic trough collectors loops at the commercial 50 MWe parabolic trough power plant AndaSol-3 in 2015. Redundant clamp-on measurements with two PT100 were mounted at the inlet and outlet of the loops under investigation. Redundant sensors were mounted with a spatial distance of $180^{\circ}$ from each other (around the pipe). The entire temperature setup for one loop was installed and dismantled during normal operation of the power plant by two trained DLR employees. The installation process took about 3 hours. At each loop, the setup remained for at least one week.

As the clamp-on system was precisely developed to overcome the lack of high accuracy inline temperature measurement in field loops, there are no reference sensors available and the measurement quality can only be judged in terms of agreement of redundant sensors. Average deviations between the redundant clamp-on sensors at the loop inlet were below $0.1 \mathrm{~K}$ and at the loop outlet of around $0.3 \mathrm{~K}$. The higher deviations at the outlet can be explained by the higher absolute temperature of up to $394^{\circ} \mathrm{C}$, compared to $294^{\circ} \mathrm{C}$ at the inlet. Additionally, despite prevailing turbulent flow, the unilateral illumination of the receivers with concentrated solar radiation can cause a slight temperature stratification at the outlet.

\section{Conclusion}

A non-invasive clamp-on measurement system for pipe surface temperature was developed for accurate temperature measurements at line focusing concentrating solar power plants without interference with the plant operation. Mechanical, flow related and mounting related influences on the measurement system were examined experimentally and theoretically. The experimental data was reduced to a function, which corrects remaining differences between the measured surface temperature and the fluid temperature. With the correction, the clampon system can measure fluid temperatures up to $400^{\circ} \mathrm{C}$ with uncertainties below $\pm 0.7 \mathrm{~K}(2 \sigma)$, if the operating conditions comply with the stated conditions.

The clamp-on system was expanded regarding wider application scenarios, supporting a variety of fluids, pipe and insulation materials, geometries and operating conditions. A dimensionless model function for the temperature correction between clamp-on sensor and fluid was developed via a dimensional analysis. The fitted model function closely matches the results obtained from an analytical heat transfer model for pipes which was validated with experimental data. In $95.5 \%$ of the cases deviations between the heat transfer model and the fitted model function are within $\pm 0.04 \mathrm{~K}$. In comparison to real clamp-on measurements with Syltherm-800, the fitted model function shows deviations below $0.1 \mathrm{~K}$ up to temperatures of about $400^{\circ} \mathrm{C}$. The results indicate that the developed clamp-on system in combination with the dimensionless correction function is suitable for various temperature measurement applications in the power and chemical industry with uncertainties below $1 \mathrm{~K}(2 \sigma)$. 
The practical applicability of the clamp-on temperature measurement system at commercial power plants was successfully demonstrated during a field measurement campaign at the $50 \mathrm{MW}_{\mathrm{el}}$ parabolic trough solar power plant AndaSol-3. 


\section{Acknowledgement}

The work presented in this publication has received funding from the German Federal Ministry for the Environment, Nature Conservation, Building and Nuclear Safety within the StaMeP project under the grant agreement no. 0325472A. We gratefully acknowledge Marquesado Solar for giving access to the Andasol-3 plant.

\section{Nomenclature}

\begin{tabular}{|c|c|c|}
\hline Symbol & Signification & unit \\
\hline \multicolumn{3}{|l|}{ Latin symbols } \\
\hline$A$ & Area & $\mathrm{m}^{2}$ \\
\hline$a_{1}$ & Parameter of correction function (factor) & - \\
\hline $\mathrm{Bi}$ & Biot number & - \\
\hline$c_{p}$ & Specific heat capacity & $\mathrm{kJ} /(\mathrm{kgK})$ \\
\hline$d$ & Diameter & $\mathrm{m}$ \\
\hline$d m, d n, d q, d v$ & Parameter of correction function (summand) & - \\
\hline$h$ & Heat transfer coefficient & $\mathrm{W} /\left(\mathrm{m}^{2} \mathrm{~K}\right)$ \\
\hline 1 & Length & $\mathrm{m}$ \\
\hline$m, n, p, q, r, s, u, v$ & Parameter of correction function (exponent) & - \\
\hline $\mathrm{Nu}$ & Nusselt number & - \\
\hline $\operatorname{Pr}$ & Prandtl number & - \\
\hline$\dot{Q}$ & Heat flow & W \\
\hline$\dot{q}^{\prime}$ & Specific heat flow & $\mathrm{W} / \mathrm{m}$ \\
\hline$\dot{q}^{\prime \prime}$ & Specific heat flow & $\mathrm{W} / \mathrm{m}^{2}$ \\
\hline$R$ & Thermal resistance & $\mathrm{K} \mathrm{m} / \mathrm{W}$ \\
\hline $\operatorname{Re}$ & Reynolds number & - \\
\hline$T$ & Temperature & ${ }^{\circ} \mathrm{C}$ \\
\hline$w$ & Velocity & $\mathrm{m} / \mathrm{s}$ \\
\hline \multicolumn{3}{|l|}{ Greek symbols } \\
\hline$\Delta$ & Difference & \\
\hline$\delta$ & Thickness & $\mathrm{m}$ \\
\hline$\varepsilon$ & Emittance & \\
\hline$\Theta$ & Dimensionless temperature & - \\
\hline$\eta$ & Dynamic viscosity & $\mathrm{kg} /(\mathrm{ms})$ \\
\hline$\lambda$ & Thermal conductivity & $\mathrm{W} /(\mathrm{mK})$ \\
\hline$\xi$ & Friction factor & - \\
\hline$\rho$ & Density & $\mathrm{kg} / \mathrm{m}^{3}$ \\
\hline$\sigma$ & Stefan-Boltzmann constant & $\mathrm{W} /\left(\mathrm{K}^{4} \mathrm{~m}^{2}\right)$ \\
\hline $1 \sigma$ or $2 \sigma$ & Coverage factor of 1 or 2 & \\
\hline \multicolumn{3}{|l|}{ Subscripts } \\
\hline air & Air & \\
\hline $\mathrm{co}$ & Clamp-on sensor & \\
\hline cond & Conductive & \\
\hline contact & Contact & \\
\hline conv & Convective & \\
\hline
\end{tabular}




\begin{tabular}{|l|l|l|}
\hline$f$ & Fluid & \\
\hline $\mathrm{i}$ & Inner & \\
\hline in & Insulation & \\
\hline $\mathrm{j}, \mathrm{k}$ & index & \\
\hline $\mathrm{o}$ & Outer & \\
\hline $\mathrm{p}$ & Pipe & \\
\hline rad & Radiative & \\
\hline ref & Reference & \\
\hline sh & Sensor holder & \\
\hline sky & Sky & \\
\hline test & Test & \\
\hline
\end{tabular}

\section{References}

[1] J. V. Beck, B. Blackwell, A. Haji-Sheikh, Comparison of some inverse heat conduction methods using experimental data, International Journal of Heat and Mass Transfer, Vol : 39, Pages 3649-3657, (1996).

[2] Wen-Lih Chen, Yu-Ching Yang, Win.Jin Chang, Haw-Long Lee, Inverse problem of estimating transient heat transfer rate on external wall of forced convection pipe, Energy Conversion and Management, Vol : 49, Pages 2117-2123, (2008).

[3] T.Lu, B.Liu, P.X. Jiang, Inverse estimation of the inner wall temperature fluctuations in a pipe elbow, Applied Thermal Engineering, Vol : 31, Pages 1976-1982, (2011).

[4] J.M. Gorman, E.M. Sparrow, J.P. Abraham, Differences between measured pipe wall surface temperatures and internal fluid temperatures., Case Studies in Thermal Engineering, Volume 1, Issue 1, Pages 13-16, (2013).

[5] Wei Cai, Zhi-Yong Yang, Wen-Hua Xu, Min-Qiang Dai, A non-intrusive oil temperature measurement method of hydraulic system, Review of Scientific Instruments 85, (2014).

[6] Fernández-García, A., Zarza, E., Valenzuela, L., Pérez, M., Parabolic-trough solar collectors and their applications, Renewable and Sustainable Energy Reviews Volume 14, Issue 7, Pages 1695-1721, (2010).

[7] Janotte N, Requirements for Representative Acceptance Tests for the Prediction of the Annual Yield of Parabolic Trough Solar Fields, doctoral dissertation RWTH Aachen University, (2012).

[8] N. Janotte, E. Lüpfert et. al., Influence of Measurement Equipment on the Uncertainty of Performance Data from Test Loops for Concentrating Solar Collectors. Journal of Solar Energy Engineering, Vol: 132, Issue: 3, (2010).

[9] Michael Geyer et al., EUROTROUGH - Parabolic Trough Collector Developed for Cost Efficient Solar Power Generation, 11th SolarPACES International Symposium on Concentrated Solar Power and Chemical Energy Technologies, Zurich, Switzerland, (2002). 
[10]P. Abraham, E.M. Sparrow, W.J. Minkowycz, Internal-flow Nusselt numbers for the lowReynolds-number end of the laminar-to-turbulent transition regime, International Journal of Heat and Mass Transfer, Vol : 54, Pages 584-588, (2011).

[11]J P Bentley, Temperature sensor characteristics and measurement system design, Journal of Physics E: Scientific Instruments, Vol : 17, (1984).

[12]K. S. Gam, I. Yang, Y.-G. Kim, Thermal Hysteresis in Thin-Film Platinum Resistance Thermometers, International Journal of Thermophysics, Vol: 32, Pages 2388-2396, (2011).

[13]D. Zvizdić, D. Šestan, Hysteresis of thin film IPRTs in the Range $100{ }^{\circ} \mathrm{C}$ to $600{ }^{\circ} \mathrm{C}$., AIP conference Proceedings 1552, (2013).

[14] Hashemian, H.M., Aging characteristics of nuclear plant RTDs and pressure transmitters, Proceedings of the fourth international topical meeting on nuclear thermal hydraulics, operations and safety, Vol : 2, (1994).

[15] German accreditation body DAkkS, DAkkS-DKD-R 5-1 Richtlinie Kalibrierung von Widerstandsthermometern (Guidline Calibration of resistance thermometers), DAkkS, (2003).

[16] German accreditation body DAkkS, DAkkS-DKD-R 5-4 Richtlinie Kalibrierung von Temeratur-Blockkalibratoren (Guidline Calibration of temperature block calibrators), DAkkS, (2010).

[17]Curtis, D.J., Thermal Hysteresis and Stress Effects in Platinum Resistance Thermometers, Temperature, Its Measurement and Control in Science and Industry, Vol : 5, Pages 803-812 (1982).

[18] Heller P, Meyer-Grünefeldt M, Ebert M, Janotte N, Nouri B, Pottler K, Prahl C, Reinalter W, Zarza E, KONTAS - A rotary test bench for standardized qualification of parabolic trough components, 17th SolarPACES International Symposium on Concentrated Solar Power and Chemical Energy Technologies, Granada, Spain, (2011).

[19] Omemah Gliah, Boguslaw Kruczek, Seyad Gh. Etemad, Jules Thibault, The effective sky temperature: an enigmatic concept, Heat Mass Transfer, Vol : 47, Issue 9, Pages 11711180, (2011).

[20] Gnielinski V, New equations for heat and mass transfer in turbulent pipe and channel flow., Int Chem Eng 16, Pages 359-368, (1976).

[21] Gnielinski V, Berechnung mittlerer Wärme- und Stoffübergangskoeffizienten an laminar und turbulent überströmten Einzelkörpern mit Hilfe einer einheitlichen Gleichung., Forschung im Ingenieurwesen, Vol : 41, Issue 5, Pages 145-153, (1975).

[22]Ain A. Sonin, The Physical Basis of DIMENSIONAL ANALYSIS Second Edition, Department of Mechanical Engineering MIT Cambridge, (2001). 
[23]Buckingham E., On physically similar systems; illustrations of the use of dimensional equations Physical Review 4, Pages 345-376, (1914).

[24] Mckay M. D., Beckman R. J., Conover W. J., Comparison of Three Methods for Selecting Values of Input Variables in the Analysis of Output From a Computer Code, Technometrics, Vol. 42, No. 1, Special 40th Anniversary Issue, Pages 55-61, (2000).

[25] Powell M.J.D., The BOBYQA algorithm for bound constrained optimization without derivatives, Department of Applied Mathematics and Theoretical Physics, Centre for Mathematical Sciences, Cambridge, (2009). 